Please do not remove this page

RMIT

UNIVERSITY

\title{
Discourses of change ownership in higher education
}

Boxer, Lionel

https://researchrepository.rmit.edu.au/esploro/outputs/9921858373601341/filesAndLinks?institution=61RMIT_INST\&index=null

Boxer, L. (2005). Discourses of change ownership in higher education. Quality Assurance in Education, 13(4), 344-352. https://doi.org/10.1108/09684880510626601

Published Version: https://doi.org/10.1108/09684880510626601

Repository homepage: https://researchrepository.rmit.edu.au

(c) Emerald Group Publishing Limited

Downloaded On 2023/04/26 20:18:29 +1000 


\title{
Quality Assurance in Education
}

\section{Discourses of Change Ownership in Higher Education}

\author{
Dr Lionel Boxer \\ Centre for Management Quality Research \\ Business Faculty \\ Royal Melbourne Institute of Technology \\ Melbourne, Victoria, Australia
}

Keywords: Positioning theory, culture, discourse, change

\begin{abstract}
:
Purpose of this paper

This paper demonstrates how the positioning of self and others affects change in higher education.

\section{Design/methodology/approach}

The discourse of various educators was collected during various interviews and discussion groups. A positioning theory framework was used to analyse the data and derive conclusions.
\end{abstract}

\section{Findings}

It is shown that if individuals are understood in terms of their agendas in relation to the organisational context that they can be better led.

\section{Research limitations/implications (if applicable)}

The quantity and quality of data available has limited the integrity of conclusions drawn from this paper. Further research is proposed that will provide a more robust understanding.

\section{Practical implications}

An approach to understand how to deal with various stakeholders is presented for leaders. There is a need to deal with each person as an individual depending on how their personal agendas influence their priorities.

\section{What is original/value of paper}

This paper introduces a social constructionist perspective to leading academics.

\section{1. $\quad$ Introduction}

This paper introduces four modes of change thought that is made by four identifiable groups involved in the higher education change debate. These modes of thought are explored in terms of the discourse produced by the groups and referred to as types of change discourses.

Each time conversations occur, the participants each reinforce or redefine themselves and the self of others involved in the encounter. Collectively and aggregately, people create themselves and others 
through discourse (Davies and Harré 1990). It is from this perspective that change can be understood as a series of issues with various players who either drive issues or resolve them.

Foucault provides a variety of ideas to understand discursive action, which have been harnessed by various social scientists and observers of radical change (Burton 1985, Hollway 1984, Murphy 1994, and Weedon 1987, Butler 1997). Davies and Harré (1990) was influenced by many of these authors. Further interpretation of Foucault's ideas led the author to develop a positioning theory framework for culture analysis and development (Boxer 2005, 2004, 2003a, 2003b, 2003c, 2002, 2001).

Discourses of change will be developed using the positioning theory framework. It will be suggested that various stakeholders engage in unique discourses about change that reflect each stakeholder group and the perceptions of individuals in those stakeholder groups. The challenge for leaders becomes the need to challenge (Boxer 2005 and 2003c) individuals and the culture in appropriate ways to keep them aligned with organisational goals.

The next Section will briefly explore Harré's positioning theory and introduce the analytical framework. Following that, stakeholder groups in the higher education change debate will be introduced. Then data representing the discourse of the various stakeholder groups will be discussed.

\section{2. $\quad$ Positioning Theory Primer}

Positioning theory concerns the way individuals are defined by themselves and others through conversation. This section follows the development of positioning theory from Foucault, the Foucauldian feminists, and Harré to the author's framework of analysis.

Foucault (1973, 1977, 1978, 1979) observes that society actively constructs individuals as docile and useable subjects in the various systems of production and control and that it is possible for individuals to challenge these conventions and define themselves in more appropriate ways. Foucault (1984, p. 369) explains that selves are 'constituted in real practices - historically analysable practices.' Hollway (1984) was first to harness these ideas to show how people have been subjugated by dominant discourse in society and suggest that it is possible to alter this imposed positioning through introducing an alternate discourse. It was from this foundation that Davies and Harré (1990) developed their seminal work, Positioning: the discursive production of selves. Butler (1997) refers to this process as a 'subject's becoming'. From this foundation and Harré's $(1979,1983)$ previous work, Harré and van Langenhove (eds., 1999) and Harré and Moghaddam (2003) have assembled a variety of interpretations and applications of positioning theory.

Harre's various works led the author to conceive Figure 1 (Boxer 2003c), which shows that when people encounter one another, they engage in discursive action that has a tri-polar nature. Discourse follows a story-line that is conducted by oneself (person) and other selves (other people), through speech acts. In an organizational context, a person's self is understood in the position that they take up in the conversation and that position may or may not change during the conversation.

\section{Take in Figure 1}

Self and other are relative discursive constructs based on a core of knowledge, which forms the basis of each individual's truth. Through this they develop a sense of ethics and become a moral agent. As shown in Figure 2, discursive action, composed of the positions individuals bring to each conversation, the story line of the conversation and various speech acts; these contribute to the redefinition of self and 
other during each encounter. As positioning occurs and positions are established, a social field of power or underlying mood is created and that mood influences subsequent encounters.

\section{Take in Figure 2}

The social constructionist model in Figure 3 demonstrates underlying mood. Discursive action and the resulting positioning take place within the underlying mood. The term underlying mood could be exchanged with underlying conscious or culture. Whereas Harré and van Langenhove (1999, p. 3) refer to this as a 'local moral order', which is composed of 'rights', 'obligations' and 'acts', the author perceives that the moral order, rights, obligations and acts are four mutually interdependent components that define a larger social order. Such a concept of social order could provide a discursive way of defining and thinking about culture of an organisation.

\section{Take in Figure 3}

With this framework in mind, discursive data can be understood as attempts to establish selves and others in an effort to alter the underlying mood about issues. In the case of change, various stakeholders engage with one another to express their views of issues in terms of an alternate discourse and attempt to modify other stakeholders or sustain their entrenched points of view. Leaders have an obligation to ensure that the underlying mood is aligned with organisational requirements (Boxer 2005 and 2003c).

\section{Modes of Higher Education Change Thought}

Change thought is here categorised into various modes. Discursive data used here was collected during an inquiry into how CEOs deal with sustainability issues (Boxer 2003c), it provides description of these modes of discourse. These data are included here italicised and in indented paragraphs. Further data is extracted from other interviews and discussions.

With that in mind, four modes of thought have been identified and located on Figure 4, where they are represented on the change framework to show their relationship between passion for change and passion for economic profit. The placement of these modes on these axes is demonstrated by the data in the subsequent sub-sections. Some modes are concerned primarily with profit and some are more inclined to be primarily concerned with change, with a few in between.

\section{Take in Figure 4}

\subsection{Mode A: Traditional Educator Discourse}

Traditional educators - whether individuals or collectively - expect quality and rigorous educational programs supported by carefully administered robust academic governance. They express concern when faced with situations that threaten the integrity of the programs they administer.

'It is wrong to make an academic leader responsible to enforce academic integrity and not be given the resources to do so. People have received academic awards - even academic awards with distinction - for work that was substandard and sometimes questionably theirs. This has happened simply because there was insufficient governance procedures or a lack of careful attendance to those procedures by those accountable.'

When they are faced with changes that do not provide for robust academic governance traditional educators predict the shortfalls that they perceive will result from such changes. 
If these changes are put in place it will leave the way open for litigious students who perceive they have been poorly served by the university. The university's awards will lose value.

While traditional educators are not hostile to change, their motivation to resist initiatives too quickly is to maintain the academic integrity of their institution and the wider academic community. While there may be a degree of personal reputation, the collective morale of academics is largely based on membership in a society of individuals who share an expectation of mutually understood standards of achievement. Traditional educators expect positioning to be a function of legitimate academic qualifications and question the introduction of alternate discourses or those undermining standards.

From this, it can be suggested that the Traditional Educator has a moderate passion for profit and a moderate passion for change. Their passion is along another dimension - academic integrity.

\subsection{Mode B: Incentive-Coerced Academic Discourse}

Barsky (2004) observes that incentives can lead managers to make bad ethical choices. That is, managers can be coerced into making bad ethical choices by rewards for performance (Gellerman 1986). Many managers, who are coerced by incentive systems, continue to ignore these contemporary moral discourses and deploy forms of power and power relations that undermine change initiatives.

In higher education, some have sufficient control over a broad range of activities to enable expenses to be allocated in such a way that illusions are created that enable them to achieve personal objectives.

You see, (they) want to visit their friends and relations overseas and they create a situation for themselves. (They) are involved in local lecturing and international lecturing. To justify their international lecturing they allocate all developmental costs to local lecturing so that their international lecturing appears to be profitable. No one looks at their local lecturing activities, because these have not attracted the same degree of scrutiny.

It is generally acknowledged by a wide range of academics that current rewards for research in Australia leads academics to produce quantities of research rather than quality research. The federal Department of Education Science and Training (DEST) awards DEST points for each approved research paper. It is the feeling of academics that, while DEST points create an incentive to conduct research, the system rewards those who produce additional publications as opposed to those who achieve eminent advancement in their field. As such, a quantity of mediocrity could replace the quality of substance as the hallmark of Australian academia.

From this, it can be suggested that the Incentive-Coerced Academic has little passion for profit and little passion for change. Their passion is along another dimension - personal gain.

\subsection{Mode C: Change Leaders Discourse}

Gibson-Graham (1996) explains how the community is subjected to the discourse of mainstream business and the identities it dictates for us. Change leaders realise this and seek to introduce alternate discourses.

I have to do a translation job; having some very general concepts or specific concepts and to be able to translate those into a language and conceptual framework that is the business plan, for social scientists, for chiropractors, for administrators in HR, administrators in finance, for administrators who are in the property area and say this is what it means to you, this is what it might start to look like for you. I have to give them enough of a start so that they can actually take the conversation on and explore for themselves. 
Within higher education there have been a number of initiatives to increase financial performance. In some cases, a wider perspective that has embraced non-financial issues has been adopted.

I have suggested that this should be symbolised in part by a changing performance measurement regimes to one that moved quite formally away from the financial bottom line approach.

It is the combined pressure of both financial and other issues that appear to collectively lead to initiate change plans.

(While the) academics like(d) to turn around structures and organisational forms, there were financial issues, there was programmatic anomalies that needed to be dealt with, there was a view that probably those together that suggested there should be a reduction in the number of faculties.

From this, it can be suggested that the Change Leader Academic has moderate passion for profit and strong passion for change. Their passion for profit may be related to the changes they are responsible for.

\subsection{Mode F: Activist Discourse}

Having learned from the global feminist movement the incredible power of small discussions in localities, change activists compete with global forces through the hopeful engagement in telling small stories at the local level. They create varying degrees of resistance in order to express hopes for now power relations. They realise they can be autonomous subjects rather than objects of development. They are well guided to operate their local resistance in certain global ways through an aggregate of local effort. They engage in deconstruction and practices of resubjectivation. They create breaches for unequal power to be introduced with the objective to destabilizing the hegemony of unsustainable practices. As deconstructionists, activists see a dominant discourse that lacks concern for change. Because they realise its colonising power, activists stand outside the main stream for a more transparent perspective.

Activists liberate society from the non-sustainable practices by creating new discourse that enable repositioning of individuals into a more sustainable approach and assume power in new forms. It becomes a project of resubjectivation; that is new institutions and practices are created for people to align with. Leaders can harness the enthusiasm of activists in cases where their interests are aligned with the strategies of the larger organistion. By doing so, the influence leaders are positioned as allies.

I am very assiduous at picking influence leaders, who are conducting debates in their own right or are involved in sub debates or subsets going on in the university.

While it is necessary to introduce persuasion for appropriate change, leaders need to beware of attempts to hijack planned work. A senior manager in higher education reflects on how activists converging their influence need to be reacted to appropriately.

There has been something going on in student politics, but nothing to do with me, and they are expecting me to afford them the offer that I have made which it is a personal and personalised response to what is a stylysed political. I must have received 100 e-mails. Well, I am not going to do it; it is about matching behaviours of integrity with behaviours of integrity while dealing with people and meeting political strategies with political strategies. If you to meet a political strategy with a personal one you will be undone, and at the end of the day your success as a change agent is whether you survived. So, clearly survival is key to actually having the capacity to employ the persistence that I talked about; if you are not in the job then it really does not matter how persistent you are. 
The manager was aware of the attempt to be drawn into irrelevant discussions and refused such positioning. Had the manager accepted the students' attempt at positioning, the manager would have become engulfed in extraneous debate and distracted from priority work.

Those senior managers who deal with change well realise that they do not have a right to ignore activists. In fact, they realise their duty to embrace and involve activists already employed in their own organisation. By establishing a moral order that respects the views of those passionate about change they encourage action that contributes to organisation-wide sustainable behaviour.

From this, it can be suggested that the Activist Academic has little passion for profit and strong passion for change. Their passion for change may be related to their perception of social justice rather than change.

\section{4. $\quad$ Conclusion}

The four categories of change discourse introduced in this paper provide an initial understanding of the different perspectives. However, more focused data would refine insight. For example, while there is evidence that such behaviour occurs in other sectors, and there is anecdotal evidence, little substantiated data was uncovered about incentive coerced academics from the data at hand. Further discursive data could be collected from interviews that focus on those stakeholders who are judged to be ethical, based on some criteria drawn from contextual values in the university or college being studied.

Even with the limited understanding gained here, leaders in academic communities can better manage the stakeholders as they are identified. For example, those with personal agendas that influence their passion need to be challenged (Boxer 2005, 2003c) to keep the objectives in mind and to ensure that necessary changes are undertaken in the way required by organisation, as opposed to personal preference. An underlying mood that acknowledges fiscal discipline and change is required.

It has been shown that various stakeholders engage in unique discourses about change that reflect each stakeholder group and the perceptions of individuals in those stakeholder groups. This understanding can be used to better understand issues and how each group treats them. With detailed contextual data, such an analysis can provide educationalists with, increased intelligence enables more appropriate decisionmaking.

\section{Reference}

Barsky, A.P. (2004) 'Understanding the Ethical Cost of Assigned Performance Goals', A thesis submitted for the degree of Doctor of Philosophy from the Graduate School, Tulane University, New Orleans, LA.

Boxer, L.J. (2005) The Sustainable Way, Brolga Publishing, Melbourne

Boxer, L.J. (2004) 'Being able to do What You Aspire to do,' in S. Charlesworth and M. Fasteanu (eds.) Women and Work, Melbourne: RMIT Publishing, pp. 75-84.

Boxer, L.J. (2003a) 'A Positioning Theory Method for Culture Analysis and Development', in L. Boxer (Ed.) $4^{\text {th }}$ International Proceedings, Multinational Alliance for the Advancement of Organisational Excellence (MAAOE) 20-22 Oct 2003, Melbourne: Intergon, published on CDRom

Boxer, L.J. (2003b) 'Using Positioning Theory to Assess Quality Systems', in R. Harré and F.M. Moghaddam (eds.) The Self and Others, Westport, Conn.: Quorum Books. 
Boxer, L.J. (2003c) 'Using Positioning Theory to Understand How Senior Managers Deal with Change', A thesis submitted for the degree of Doctor of Philosophy from the Royal Melbourne Institute of Technology, Faculty of Business, Melbourne.

Boxer, L.J. (2002) 'Improving Education Quality with Positioning Theory', in the proceedings of Transforming Quality: $7^{\text {th }}$ Annual Quality in Higher Education Seminar, Royal Melbourne Institute of Technology, 30-31 Oct 2002.

Boxer, L.J. (2002) 'Improving Information Flow with Positioning Theory', in P. Coleshill (ed.) Organisational Excellence: Managing Information, $3^{\text {rd }}$ International Proceedings, Multinational Alliance for the Advancement of Organisational Excellence (MAAOE) 11-13 Sep 2002, Ayr: University of Paisley.

Boxer, L.J. (2002) 'Assessment of Quality Management Systems with Positioning Theory', Proceedings of the $7^{\text {th }}$ International Conference on ISO9000 and TQM, Melbourne, Apr 2002.

Boxer, L.J. (2001) 'Using Positioning Theory to Make Change Happen', in M. Terziovski (ed.) Proceedings of the $5^{\text {th }}$ International and $8^{\text {th }}$ National Conference on Quality and Innovation Management, Faculty of Economics and Finance, 12-14 Feb 2001, Melbourne: University of Melbourne.

Butler, J. (1997) The Psychic Life of Power: theories in subjection, Stanford University Press, Stanford, California.

Burton, C. (1985) Subordination: feminism and social theory, Sydney: George Allen and Urwin.

Davies, B. \& R, Harré (1990) 'Positioning: The discursive production of selves', Journal for the Theory of Social Behaviour, 20(1), pp. 44-63, http://www.massey.ac.nz/ ALock/position/position.htm, accessed 11 Sept 1999.

Foucault, M.( 1973) The Birth of the Clinic: An archaeology of medical perception, (trans.) A.M Sheridan Smith, New York: Pantheon Books,

Foucault, M. (1977) Discipline and Punish: The birth of the prison, (trans.) A. Sheridan, New York: Pantheon Books.

Foucault, M. (1978) History of Sexuality Vol 1, New York: Random House.

Foucault, M. (1979) ‘Governmentality’, Ideology and Consciousness, Vol. 6, No. 3, pp. 5-21.

Foucault, M. (1984) 'On the genealogy of ethics: an overview of work in progress', in The Foucault Reader, (ed) P. Rabinow, Pantheon, New York, pp. 340-72.

Friedman, M. (1970) 'The Social Responsibility of business is to increase its profits', New York Times, 13 Sep 1970.

Gellerman, S.W. (1986) 'Why “good” managers make bad ethical choices’, Harvard Business Review, , Jul/Aug 1986, Col. 64, No. 4, pp. 85-90.

Gibson-Graham, J.K. (1997) The end of capitalism (as we knew it): a feminist critique of political economy, Blackwell, Cambridge, Massachussetts.

Harré, R. 1979, Social Being, Blackwell, Oxford

Harré, R. 1983, Personal Being, Blackwell, Oxford

Harré, R. and L. van Langenhove (eds.) (1999) Positioning Theory: Moral contexts of intentional action, written by Berman L et al, Oxford: Blackwell Publishers.

Harré, R. and F.M. Moghaddam (2003) The Self and Others, Westport, Conn.: Quorum Books. 
Hollway, W. 1984, 'Gender differences and the production of subjectivity', in (eds.) J. Henriques, W. Hollway, C. Urwin, L. Venn and V. Walkerdine, Changing the Subject: Psychology, social regulation and subjectivity, Methuen, London, pp. 227-63

Murphy, C.C. (1994) An Introduction to Christian Feminism, Dominican Publications, Dublin

Weedon, C. (1987) Feminist Practice and Poststructuralist Theory, Basil Blackwell Ltd, Oxford 


\section{Bio}

Lionel Boxer CD PhD MBA BTech(IE) has consulted to business and government since 1981 through Intergon - his private consultancy - and several multi-national professional service firms. He is a research fellow with the Royal Melbourne Institute of Technology (RMIT) Centre for Management Quality Research and adjunct staff of the RMIT Graduate Management School. He has published conference papers, book chapters and a book, The Sustainable Way. He studied industrial engineering at the Royal Military College of Canada and Ryerson Polytechnic University and business at RMIT. In 1993 he was listed in the International Who's Who of Quality and was made a Fellow of the Quality Society of Australasia. He contributes to a variety of community and voluntary groups and continues to serve as an officer and bagpiper in the Australian Army Reserve after 20 years intermittent service in the Canadian Army.

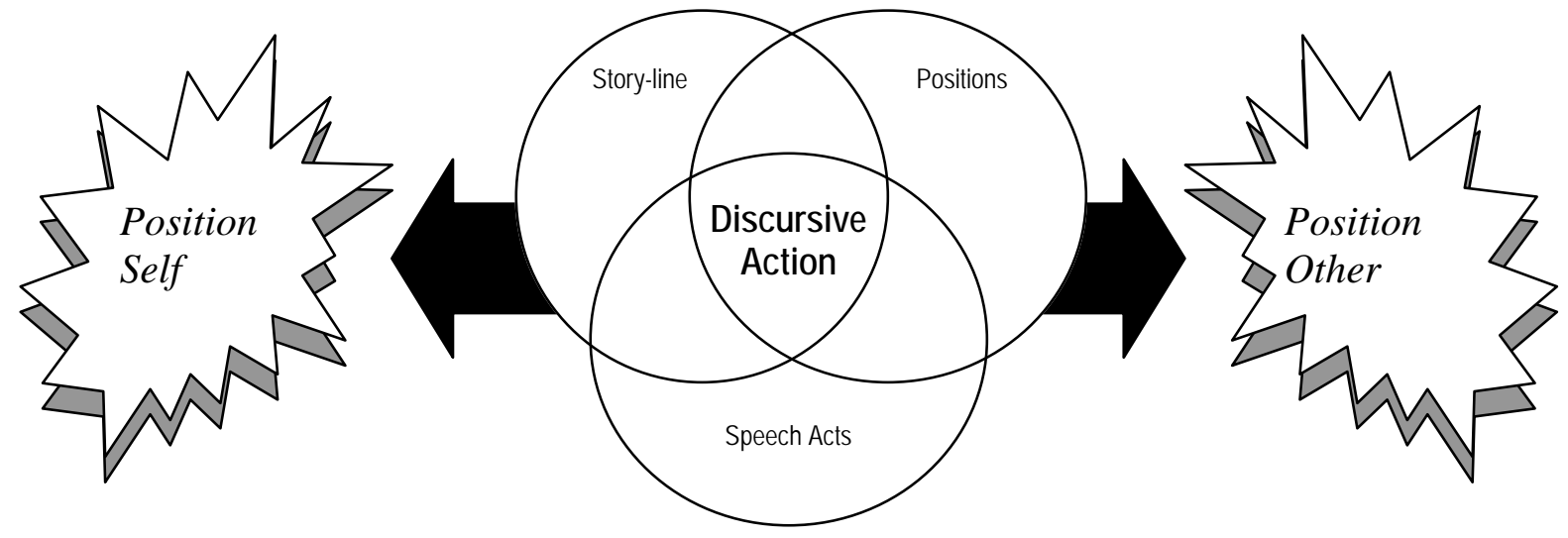

Figure 1

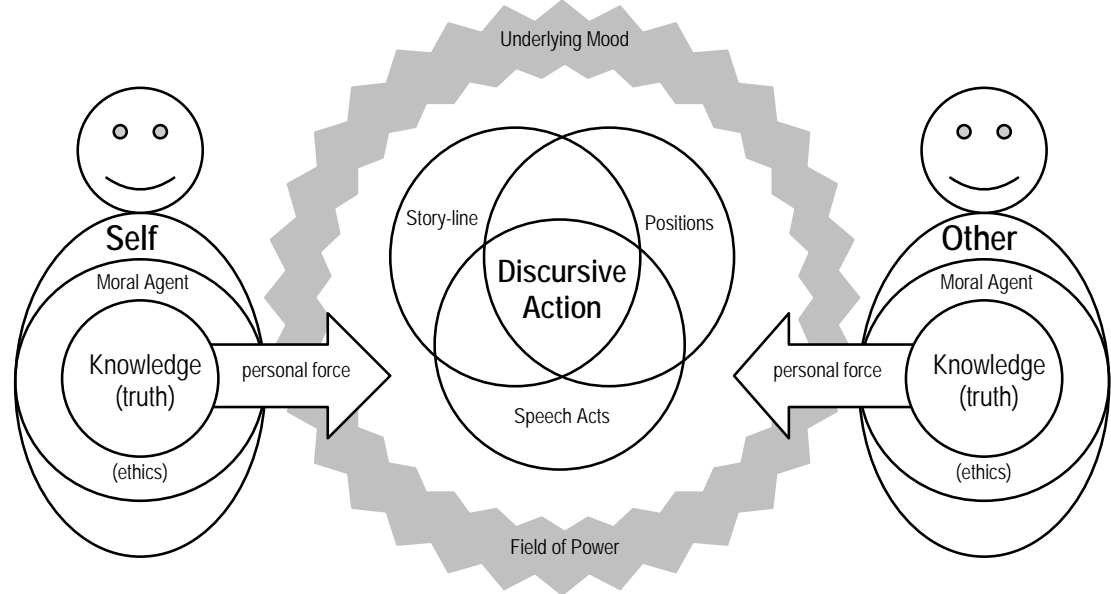

Figure 2

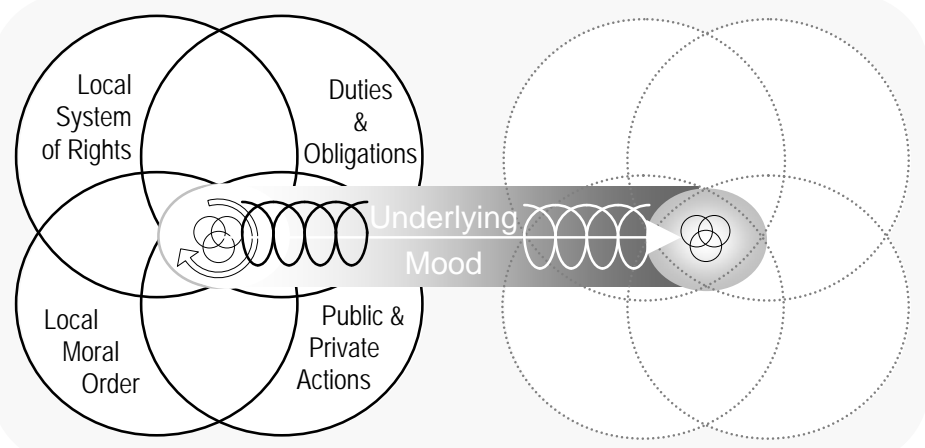

Figure 3 


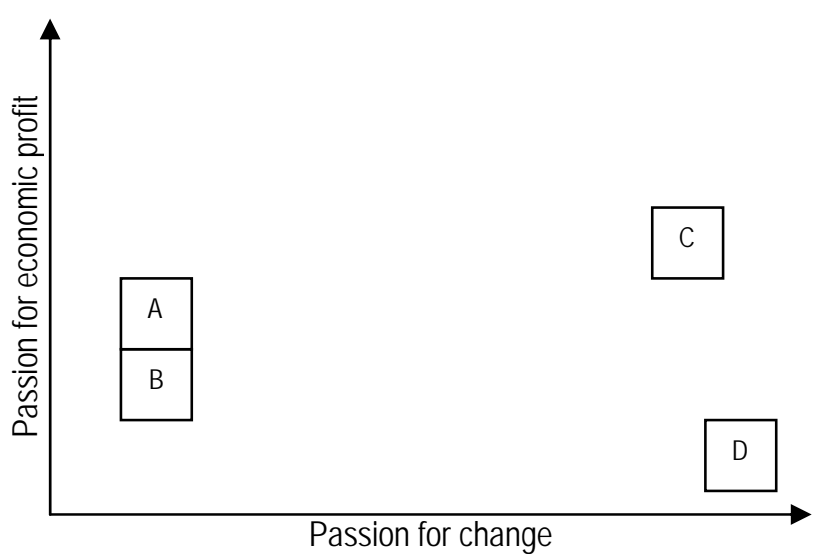

\begin{tabular}{|cl|}
\hline Mode & \multicolumn{1}{c|}{ Mode of Discourse } \\
A & Traditional Educator Discourse \\
B & Incentive Coerced Academic Discourse \\
C & Change Leader Discourse \\
D & Activist Discourse \\
& \\
\hline
\end{tabular}

Figure 4 